\title{
Ruy Ribeiro Franco: o início da Geociências
}

\author{
7 studos Apanfados - $O$ senbor foi alunzo da segunda turma do curso \\ de História Natural da Faculdade de Filosofia, Cilncias e Letras da \\ USP, na década de 30. Por que nela se matriculou? Como foi sua trajetoria \\ na Faculalade?
}

Ruy Ribeiro Franco - Em Campinas, SP, onde fiz o curso secundário no ginásio estadual Culto à Cilncia, o excelente professor Paulo Decourt despertou em mim o interesse por Mineralogia. Quando soube que na recém-criada Faculdade de Filosofia, Ciências e Letras havia um setor de História Natural e uma cadeira de Mineralogia, decidi matricular-me. Entendi que nessa Faculdade encontraria uma porta aberta para a realização de meus objetivos.

Ingressei na Faculdade em 1936. Um ano depois fui indicado para monitor. A monitoria era um serviço prestado às cátedras pelos alunos mais adiantados. Depois de graduar-me passei a assistente, posteriormente doutorei-me, fiz a livre-docência e terminei como catedrático sempre na área das Geociências. Dediquei grande parte de minha vida (trinta anos) à Faculdade de Filosofia, Ciências e Letras da USP como aluno e docente.

Já aposentado pela USP, em 1966, Dr. Romulo Ribeiro Pieroni convidou-me para dirigir os cursos de pós-graduaçáo em ciências nucleares no Instituto de Energia Atômica (o atual Ipen). Lá ministrei cursos sobre os minerais utilizados na produçáo de energia nuclear urânio e tório. Fiquei nesse Instituto vinte e quatro anos, até ser aposentado compulsoriamente, aos setenta anos.

\section{A influência dos professores do exterior}

$E A$ - Que professores foram decisidos na sua formafäo na USP? $O$ que - sembor pode contar a respeito dos professores estrangeiros que vieram dar os primeiros cursos na Faculdade de Filosofia?

$R R F$ - Um professor influiu de forma considerável em minha formação - o italiano Dr. Ettore Onorato, uma das figuras mais destacadas entre os mestres estrangeiros que vieram estruturar a Faculdade de Filosofia, a partir de 1934. Coube ao professor Onorato a responsabi- 
lidade pelos cursos de Mineralogia e Petrografia. Impressionou-me como ser humano e, como professor, devido a sua capacidade didática e competência em orientar o trabalho de pesquisa. A ele, a USP muito deve. Outros mestres que vieram do exterior igualmente foram decisivos. Entre eles, o Dr. Otorino De Fiori Coprani, um nobre italiano (baráo), especialista em vulcóes, de renome internacional. Como no Brasil não há vulcōes ativos, o professor De Fiori concentrou-se em outras áreas da Geociências, principalmente em Paleontologia.

O convívio com os professores estrangeiros era bom, produtivo e muito amigável. Não se limitava às aulas $\mathbf{e}$ ao trabalho nos laboratórios. O professor Onorato, que residia no Hotel São Bento, com freqüuência ia a minha casa. Com ele e a esposa, dona Lina, fazíamos reuniốes em minha residência. Estabeleci com esse casal excelente relação de amizade. Em geral, os alunos da Faculdade conviviam muito de perto com os professores franceses, alemães, italianos e de outras nacionalidades. Alguns desses mestres ficaram muitos anos no Brasil, outros tiveram de regressar a seus países em decorrência da Segunda Grande Guerra.

$E A$ - Como era o curso na Faculdade, em que linguas cram dadas as aulas? Como eram a carga horairia, as turmas e o trabalho nos laboratbrios?

$R R F$ - Em nossa seção, com os professores italianos, as aulas eram em italiano. Para os alunos, isso não representava problema, pelo fato de esse idioma ser acessível. Os professores franceses ministravam seus cursos em seu idioma. Recordo bem as aulas do professor Pierre Monbeig, por exemplo. Paulatinamente esses professores estrangeiros aprenderam o português. $O$ fato de as aulas serem ministradas em outros idiomas foi até positivo por propiciar aprender essas línguas.

As turmas de alunos eram pequenas. Na História Natural havia vinte vagas. Para compor a primeira turma, o governo do estado de São Paulo chamou professores secundários de escolas públicas, como Maria de Lourdes Canto, Rosina de Barros, Michel Pedro Sawaya e João Batista Piovesan. Escolhidos, fizeram o curso, como bolsistas. Em 1936, para compor a segunda turma, houve vestibular e três foram aprovados para o curso de História Natural: Armando Wohlers, Gilberto Galvão e eu. Em determinado ano, houve uma turma com um único aluno. A Faculdade de Filosofia, Ciências e Letras, em sua fase inicial contava com poucos alunos porque seus objetivos não eram bem conhecidos e os estudantes ainda procuravam os cursos tradicionais - Medicina, Direito, Engenharia Odontologia, entre outros. Nossa faculdade ainda não possuía uma identidade. Aos poucos, o quadro se alterou. Seu prestígio foi crescendo e com isso aumentou a procura pelos cursos de Química, 
Física, História Natural, Filosofia, Sociologia, línguas e outros, passando as turmas a ter número expressivo de estudantes.

Na Faculdade de Filosofia, os professores e alunos dedicavam-se em regime de tempo integral. As aulas eram pela manhã ou no período da tarde. Pesquisávamos em laboratórios, fazendo cortes nos minérios ou estudando as coleçóes mineralógicas. $O$ fato de pesquisarmos intensamente foi fundamental, possibilitando a que diversos alunos se tornassem bons professores nos ginásios, um dos objetivos da Faculdade de Filosofia, Ciências e Letras.

\section{O laboratório de Mineralogia}

EA - Professor, na fase inicial da Faculdade de Filosofia, onde funcionou o laboratorio de Mineralogia?

$R R F$ - Quando o professor Ettore Onorato chegou a São Paulo, a cadeira de Mineralogia funcionou no terceiro andar da Faculdade de Medicina e aí se instalou quase toda a Faculdade de Filosofia. Depois, fomos para a alameda Glete, para a residência que fora do Sr. Jorge Street, onde permanecemos vários anos, até a transferência para o campus do Butantan, para a Cidade Universitária, construída pelo professor Dr. Ernesto de Souza Campos. O laboratório de Mineralogia nunca funcionou no prédio da rua Maria Antônia.

Pessoalmente, trabalhei na Maria Antônia quando assumi a direçáo da Faculdade, entre os anos de 1964 e 1966, uma fase dificílima, devido aos choques com alunos do Mackenzie. Eu era o diretor em exercício da Faculdade de Filosofia. Afirmavam que nossa Faculdade era um reduto comunista. As provocaçóes culminaram com a destruiçáo do prédio da Faculdade, na rua Maria Antônia. Nessa ocasião, eu já não era professor, nem diretor, havia me aposentado.

\section{O contato entre docentes}

e pesquisadores das diversas áreas

EA - Na Faculdade de Filosofia, bavia contato permanente entre os docentes e pesquisadores das dipersas áreas? Existia entre eles intercambio de opinióes e de informaçốes?

$R R F$ - Sim, sempre houve uma ligaçáo estreita entre biólogos, físicos, químicos, pesquisadores e professores de outras áreas, o que facilitava a realização de atividades conjuntas, interdisciplinares. Cito um exemplo: durante a II Grande Guerra, a Marinha brasileira teve necessidade de fabricar aparelhos capazes de detectar a presença de sub- 
marinos. Naquela época não havia entre nós tecnologia para tanto e, assim, a Marinha recorreu à USP. Os físicos - como os professores Marcelo Damy e Paulus Aulus Pompéia - desenvolveram esses sonares e coube a mim, que estava na direção da Cadeira de Mineralogia, preparar e cortar os sais de Rochelle. Naquela oportunidade, trabalhei intensamente em colaboração com os físicos. A fabricação de sonares foi pessoalmente dirigida pelo entáo reitor da USP, professor Jorge Americano. Ele ia com frequiência aos laboratórios para colaborar no que fosse preciso, pois conhecia a importância daquela pesquisa para a Marinha brasileira. Aí está um exemplo de trabalho de ciência aplicada, que teve resultado positivo. Também os químicos colaboraram na fabricação dos sonares, os professores Heinrich Rheinboldt e Heinrich Hauptmann nos auxiliaram naquele trabalho interdisciplinar. Assim, há histórias muito interessantes na memória da Faculdade de Filosofia, Ciências e Letras da USP.

EA - Professor, os alunos da Faculdade, de determinada segáo, eram obrigados a frequientar as aulas em outras seföes? Por que os alunos da antiga Faculdade de Filosofia adquiriram uma formafăo mais ampla, universitdria?

$R R F$ - Na Faculdade de Filosofia não tínhamos a obrigação de seguir as aulas nas outras áreas, mas assistíamos às conferências dos mestres estrangeiros e de professores brasileiros. Vindo da Alemanha, 0 professor Rheinboldt foi o primeiro a chegar, instalada a cátedra de Química, dando a ela grande e merecido prestígio.

Teodoro Ramos, da Escola Politécnica, foi quem escolheu na Europa os professores estrangeiros que vieram dirigir e ministrar aulas na FFCL. Houve, portanto, acerto nessa seleção de professores, como se comprova pela trajetória da USP, graças aos alemães, aos franceses como Pierre Monbeig e Levi-Strauss - aos italianos, e aos demais. Tive a sorte de conviver com esses professores que trouxeram para o Brasil o padrão de ensino e pesquisa das universidades européias.

\section{A formação em áreas de Geociências antes da FFCL}

EA - Nas áreas das Geociencias - antes da fundaçäo da Faculdade de Filosofia - que outras escolas contributram para formar profissionais de alto nivel?

$R R F$ - Em primeiro lugar, a Escola de Minas de Ouro Preto, famosa ainda hoje, criada no século passado, por D. Pedro II, que trouxe para dirigi-la um cientista francês - Henri Gorceix (1842-1919). Essa escola graduou elevado número de engenheiros de minas que contribuí- 
ram para o progresso do país em diversos setores da Engenharia, capazes de impulsionar a produção mineral no Brasil. Correspondia, portanto, à demanda nacional de recursos humanos no setor mineral. Também foi grande a contribuição das Escolas Politécnicas do Rio de Janeiro, de São Paulo e da Bahia. Na Politécnica de São Paulo houve um excelente professor, que deu relevo à cátedra de engenharia de Minas - Dr. Luiz Flores de Morais Rego. Foi responsável pela formação de muitas turmas com ótimos profissionais. Seu sucessor na cátedra, professor Otávio Barbosa, veio da tradicional escola de Ouro Preto. Este, igualmente,

Ettore Onorato

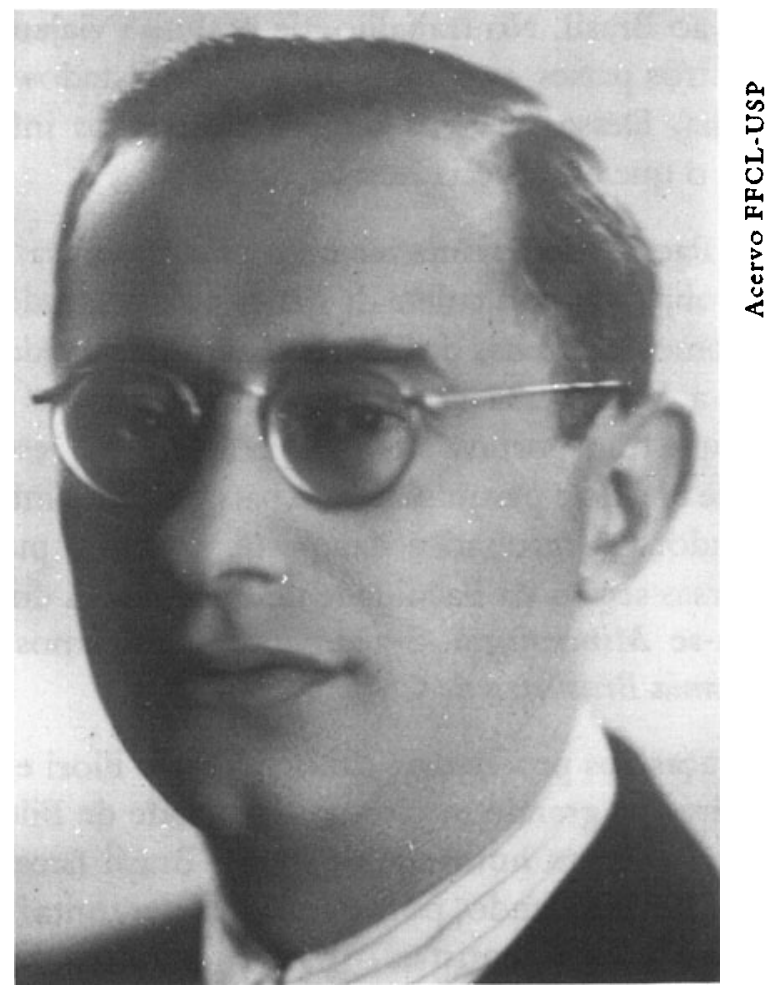

teve papel importante na formação de recursos humanos para esse setor da engenharia brasileira.

EA - Como era o trabalbo de pesquisa em Mineralogia? Em que medida, dando enfase à pesquisa, a criagăo da Faculdade de Filosofia, Cienciase Letras marcou uma nopa etapa na vida universitaria brasileira?

$R R F$ - As atividades na seção de Mineralogia, sob a direção do professor Onorato, foram intensas - na pesquisa e no ensino. De Fiori, professor de todos nós, teve como assistente e colaborador o Dr. Josué 
Camargo Mendes, recentemente falecido. Aluno em uma das primeiras turmas, posteriormente tornou-se um dos bons docentes da Faculdade.

Posso citar aqui uma de nossas pesquisas em Mineralogia - a das gemas brasileiras. As pedras preciosas - rubi, safira, diamante, e outras - são minerais dos quais o Brasil possui grandes reservas, sendo um dos maiores produtores mundiais desses valiosíssimos bens. Em razăo das pesquisas realizadas na Faculdade, passei a ministrar cursos sobre gemas e em 1955 acabei por colaborar na organizaçáo da Associação Brasileira de Gemologia, através da qual ministramos cursos em várias cidades. Essa entidade é fruto da Faculdade de Filosofia, prestando relevantes serviços ao Brasil. No trabalho de pesquisa viajamos muito pelo Brasil e por outros países - como Chile, Itália, Estados Unidos da América e Alemanha. Dessas viagens sempre trouxemos informaçóes e conhecimentos, o que enriquecia nossos cursos.

A Faculdade possuía recursos para pesquisa. Viajávamos com freqüência objetivando a coleta de materiais e o estudo de estruturas geológicas. Fomos a dezenas de lugares. Eram viagens de estudo, como as que fizemos a Vila Velha (PR). Para tais excursóes dispúnhamos de um ónibus, que transportava alunos e professores. Desenvolvíamos uma atividade de ensino e pesquisa para o país e eu me sinto feliz por dela haver participado. Os resultados das pesquisas eram publicados nas revistas das diversas seçóes da Faculdade de Filosofia. A do nosso departamento chamava-se Mineralogia. Igualmente, divulgamos trabalhos na Repista da Acadomia Brasileira de Cilncias.

Graças aos professores Onorato e De Fiori e a outros professores estrangeiros, o grande mérito da Faculdade de Filosofia residiu na formaçáo de recursos humanos de que o Brasil necessitava no campo da pesquisa. Respondendo, portanto, à sua pergunta: a Faculdade de Filosofia formou bons cientistas - físicos, químicos, biólogos, matemáticos e geólogos, bem como excelentes pensadores - filbsofos, sociólogos, historiadores. Assim, o Brasil muito deve à iniciativa de Armando de Salles Oliveira de criar a USP e a Faculdade de Filosofia.

A criação da Faculdade de Filosofia, Ciências e Letras, em 1934, assinala $\mathrm{o}$ início de uma nova fase das Geociências, no país, porque sua meta era ambiciosa. Seu propósito era formar pesquisadores para, em colaboraçáo com profissionais tecnologicamente habilitados e voltados para as atividades da produçáo mineral, exercer atividades como a exploraçäo de jazidas.

O professor Ettore Onorato deu novo impulso à Mineralogia no Brasil, sempre ensinando como realizar pesquisa científica e como for- 
mar recursos humanos para as Geociências. Devido à minha especializaçáo em Mineralogia entre 1936 a 1940, fui destacado para assistente de Ettore Onorato. Este, quando chegou ao Brasil, no início de 1935, teve como primeiro assistente o professor Reynaldo Ramos de Saldanha da Gama (engenheiro formado pela Escola Politécnica do Rio de Janeiro). Quando Onorato regressou à Itália, em 1940, a cadeira foi desdobrada em duas: o professor Reynaldo Saldanha da Gama assumiu a docência de Mineralogia e eu a de Petrologia.

$E A$ - Como o senbor analisa a saida da Faculdade de Filosofia das dreas de cilncias - Fisica, Quimica, Biologia etc.?

$R R F$ - Como um fato natural, tendo em vista o crescimento dessa Faculdade. Houve divergência sobre o assunto, mas certas áreas, para se desenvolverem, reclamavam a criação de institutos isolados, como é o caso da Física, da Química, da Geociências, entre outras. Tudo isso passou e a USP está em pleno funcionamento. Acreditamos que o desmembramento da Faculdade de Filosofia, Ciências e Letras da USP, em institutos e a Faculdade de Filosofia, Letras e Ciências Humanas, ocorrido há alguns anos, não alterou seus objetivos iniciais (1934). $O$ ensino, as atividades culturais e de pesquisa continuam os mesmos. Os fatos sucederam-se naturalmente, como em uma família. No princípio, o casal e os filhos vivem juntos. Com o passar dos anos, os filhos váo se casando e criando novas famílias sem, entretanto, romper com o núcleo

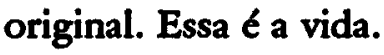

